\title{
A spreadsheet based simulator for experiential learning in production management
}

\author{
Chuda Basnet and John L. Scott \\ University of Waikato
}

This paper presents a spreadsheet based simulation game for teaching and learning production management concepts of forecasting, material requirements planning, order review and release. In this game the student plays the role of a production planner managing two products, for which customer orders are placed in variable quantities throughout the week. The student builds forecasting and material requirement planning systems to help in the tasks of production and vendor order release. In parallel with this, we have run a small learning awareness program, to test and stimulate the skill of reflection. Initial student responses to the game have been favourable, but the proportion of time spent on reflection is low. Contemplated refinements are presented.

\section{Introduction}

Simulation games are activities designed to mimic the reality of the external world, within the classroom, with the goal of instruction. The learning is intended to be experiential - the student experiences the studied phenomenon and learning proceeds inductively. Besides simulation games, there are other means of providing the experience of reality to students - case study, role playing, in basket method, and incident process. The main advantage of simulation games over these alternates is the dynamic nature of the games - the incorporation of the time element, imitating the passage of time. Students have to live with the results of their past decisions - the effects of these decisions persist into the future in the game. Another advantage is the verisimilitude offered - some games are able to provide a high level of make believe and fantasising. The strong interest that is aroused in the subject matter is itself of pedagogical value. A simulation game can be restarted with a new strategy for playing the game, but a case study can only be used once (Gilgeous and D'Cruz, 1996). 
While there are many top management games available for students and teachers of management, the number of games aiming to teach/learn specific management skills is small. There is also a dearth of games that enhance detailed modelling and decision making capability. The primary goal of the research presented in this paper is to develop a simulation game that meets this void, in the specific area of management of production planning and control, and to explore the learning implications of the game. The paper describes the game that we developed. This game is able to impart an understanding of the issues in order-release; and as a secondary benefit, the spreadsheeting skills of the students are enhanced. The paper also describes the learning experiences of the students, with an emphasis on reflection, and their evaluation of the simulation game.

\section{Literature review}

The first simulation game for teaching business management appears to have been introduced in 1955. This game, called Monopologs, was developed by the Rand Corporation for teaching logistics to U.S Air Force personnel (Faria, 1990). In 1956, the American Management Association introduced its Top Management Business Game, which was meant for training top management, and included decisions on production, marketing, assets, inventory, etc. The computations were performed on an IBM 650 computer (Kibbee, Craft \& Nanus, 1961). In this game, the players filled a form indicating their decisions, this information was punched into cards, and the computer program was run. The computer provided performance reports, and the cycle was repeated. By 1961, Kibbee et al. (1961) listed 31 computerised business games, five of which were production simulators. Since then there has been a steady increase in the number, sophistication, and adoption of simulation games (Faria, 1987; McKenna, 1991; Burgess, 1991, Wolfe, 1993).

There is now a wide range in the complexity of simulation games: from board games to computerised simulations. Even the simple act of walking may serve as a simulation for instructional purposes $(\mathrm{Wu}, 1988)$ ! While a simulation mimics reality and is often used to predict what would happen in a given scenario, the word "game" suggests playfulness and competition. Simulation games combine these two characteristics. Games that explore business strategies for the entire organisation are called top management games, and games that have their primary focus on a selected functional area of business are called functional games. These functional games are available in the areas of accounting/finance, marketing, production, and human resource management. 
The model of experiential learning provides a theoretical underpinning of simulation games as a learning/teaching tool. Kolb's (1984) experiential learning model is shown in Figure 1. According to this model, concrete experience of a phenomenon in the real world triggers the learning cycle. This event is observed/experienced, and causes/encourages reflection in the student. The student forms/uses abstract concepts and models/hypotheses to make sense of reality. This leads to experimentation and hypothesis testing that provides concrete experience, which starts the cycle again. Simulation games provide the concrete experience needed in Kolb's model, and are a good platform for stimulating learning awareness in students, encouraging them to better understand their own learning processes (Scott, 2002).

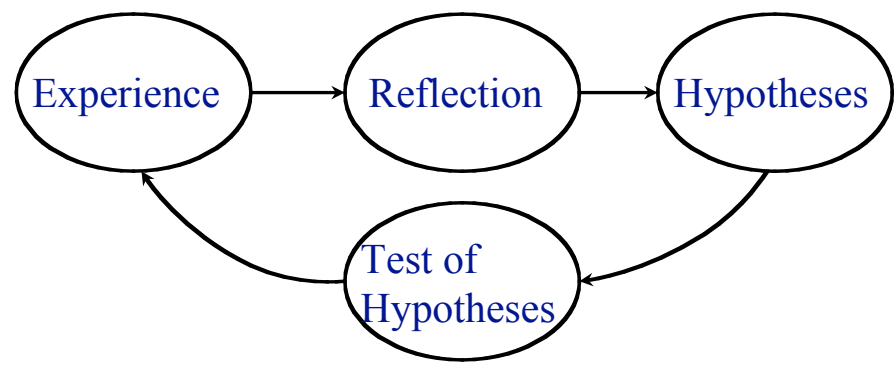

Figure 1: Experiential learning (EL) cycle model

Raia (1966), in his often cited study, carried out an experimental comparison between a simple game, a complex game, and readings. Boseman and Schellenberger (1974) used modified Raia's instruments to compare students who did only cases against students who did cases and games. Attempts were made to equalise the workload. They did not find the interest of game players any higher than non-game players. Their attitudes towards cases, management, course, and the instructors were not significantly different. Similar results were obtained for perceived or actual learning.

Wolfe and Guth (1975) made an experimental comparison between case only and game only approaches to teaching business policy. In their study, the game only students achieved a higher level of examination scores than the case only students. Students in the game only section achieved a higher degree of principle and concept mastery, but the differences in fact mastery were not significant. However, their games only section had a lot of structure - periodic reporting, class discussions of events, review sessions, self appraisals, and diary of events. This structure and guidance essentially closed the loop of experiential learning (Figure 1) and may have contributed to the positive result as 
evidenced by a subsequent study (Wolfe, 1975), which did not have this guidance, and had a negative result.

Parsuraman (1981) classifies the existing evaluation of simulation games into three methodologies:

1. Experimental evaluation, where the students are split into different groups which are exposed to different educational techniques. The efficacy of the techniques is then judged by a common examination at the end. Most of this type of evaluation has been inconclusive, and Parsuraman criticised it on the grounds that the common examinations test cognitive learning of the students, while simulation games actually teach the "process" of decision making (and not cognitive learning).

2. Correlation between students' performances in the simulation games and their performances in other examinations and assignments in the course. Here, Parsuraman questions the simulation game performance as a measure of learning.

3. Surveys of student self reports. Generally, these surveys have shown simulation games on a positive light, but the ability of the students to judge the worth of games is questionable. Parsuraman concludes that the evaluations should actually test the appearance of reality in the games, and the worth of the types of decisions made in the games. $\mathrm{He}$ suggests that experienced practitioners, not college students, are better judges.

Ruohomäki (1995) discusses the use of simulation games from the viewpoint of learning theory. A simulation game combines the features of games (competition, cooperation, rules, participants, roles) and simulation (abstraction of reality by a model). Simulation games are used when there are no possibilities for students to obtain experience of the systems or situations in the real life - where reality is too expensive, complex, dangerous, fast, or slow. Ruohomäki identifies two purposes for simulation games: 1) understanding of reality - to describe, analyse, and evaluate realities, and 2) training - learn procedures, and carry them to work activities. To achieve these, a simulation game should include orientation to the game prior to the game, the game, a debriefing consisting of reflections and observations, and forming concepts and generalisations, and integration. Simulation games can provide an opportunity for the active experimentation phase of the experiential learning cycle. Participants can try out new solutions, and see the probable consequences. 
According to Ruohomäki, simulation games provide: 1) cognitive learning outcomes - information, principles, critical thinking, 2) attitude changes toward the subject matter, society, and oneself, 3) increased motivation and interest towards the subject, for doing research in that field, and 4) positive effects on groups - better communication interactional skills, empathy for those in other roles. Simulation games provide active learning (versus passive learning in lectures). Thus they provide student centred learning, and emphasise learning by doing.

Finally, Lane (1995) in a review of simulation games has crystallised some of the cautions to be exercised in the educational use of games:

1. Learning objectives. It is easy to be sold by the gimmicks and fun in the games, but what will be learnt?

2. Supporting materials. There should be enough learning materials to support the game's objectives.

3. Other pedagogical tools. It cannot be expected that simulation games will serve all the needs of a course. At best they will supplement a well-designed course.

4. Bells and whistles. So much seductive technology is available that it is possible for the designers to be looking for appropriate topics for the technology, rather than finding suitable technology for the teaching objectives in hand. The use of animation, multimedia, and virtual reality may provide more fun than education.

5. Complexity. It is better to have a simple game serving a specific learning objective, than a complex game satisfying a number of objectives. Students may find it hard to capture the desired experience.

6. Briefing and debriefing. Evaluation of simulation games has shown time and again the importance of proper briefing and debriefing. Students cannot be left to decide on the rationale of the game, and to reflect on what happened.

7. Facilitators. The facilitators need to understand the simulations and learning objectives thoroughly. Games cannot teach by themselves.

8. Resources. Computer software is famously known for underestimating the resource requirements. Games designers need to beware.

To conclude this literature review, in spite of many anecdotal success stories and apparent student enthusiasm with games, the objective, experimental evaluation of game based instruction, particularly as compared with case based instruction, remains inconclusive. Obviously, it is more difficult to control for the quality of games as compared to the quality of cases, for the instructional style and structure, and for the enthusiasm on the part of the students and the instructor. Post-game counselling and review appears to make a definite positive impact on the effectiveness of gaming. The literature generally supports the notion that 
students usually find gaming enjoyable in spite of the considerable time taken up by it, and a well-conducted simulation game is at least not worse than a case study in providing experiential learning. Therefore judicious use of both cases and simulation games in the classroom, taking heed of the experience of others, should bring out the benefit of both techniques in the development of managerial skills.

\section{Production management games}

There are many production management games available for educational purposes, but the number has not grown in keeping with the growth in numbers for top management games and for marketing games. The available games, such as Joblot (Churchill, 1970), PROSIM (Mize et al., 1971), DECIDE-P/OM (Biggs, 1987) provide an understanding of production systems more at the strategic level than at the tactical level, as discrete event dynamic systems. There is a dearth of games designed to teach specific technical skills in production management. Lane (1995) in a pedagogical review of simulation games, referred to earlier, has supported such a simple game serving a specific learning objective, against a complex game satisfying a number of objectives. This paper presents such a game, with the objective of learning about order release in production management. A feature of this game is that students build their own decision support system (DSS) to play it. Building a DSS provides the game players with a detailed modelling and decision making capability (Yeo and Nah, 1992). This DSS is based on a specific model, material requirements planning (MRP). Teaching MRP is a goal of the game.

Beginning students of production planning and control (PPC) often struggle with the technical concepts in PPC such as bill of materials, order review and release, and action buckets, to name just a few. The students need to see how forecasting leads to master production schedule, and to material requirements planning, and finally to order release. An important objective for the students is to appreciate the variability and dynamics of the production environment, where for example even the forecast is not a static input to production planning. A simulation game is ideal for this appreciation. Such a simulation game would be a more specific and simpler game, compared to the larger production games mentioned above, which attempt to give a flavour of the entire production management function and even its strategic significance.

In this paper we present a spreadsheet based production planning simulator called MRP-SIM, designed to meet the above objective. The next section presents a description of the game. This is followed by the 
learning awareness program we ran in parallel and a student evaluation of the game. Finally, concluding remarks are presented.

\section{The game}

\section{Objectives}

The game is designed to enhance the understanding of PPC concepts such as bill of materials, routing, order review and release, priority setting, queuing, forecasting, master production scheduling (MPS) material requirements planning (MRP), and capacity requirements planning (CRP). These concepts are usually treated in isolation as discrete concepts. The simulation brings out their interactions in a simple, yet realistic setting.
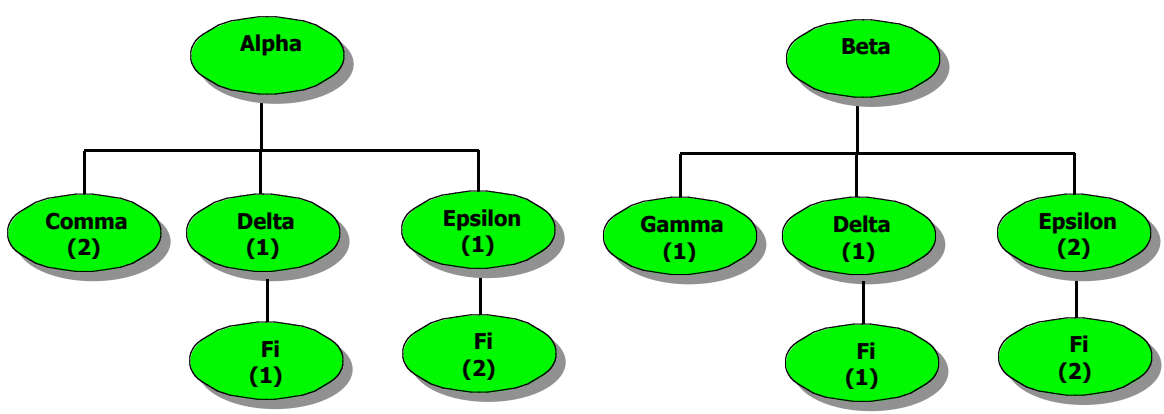

Figure 2: Bill of materials

\section{The scenario}

In this game the students play the role of the production planner of a manufacturing company. They manage two products, Alpha and Beta for which customer orders are placed on the company in variable quantities throughout the week. These products are made up of components (Comma, Delta, Epsilon, Fi, and Gamma), some of which are produced within the company, and others are sourced from vendors. In carrying out the production, the parts are routed through processing machines (Kappa, Mu, Pi, Rho, and Sigma) within the company, where processing time is spent, and queues are built up. The bill of materials is shown in Figure 2, and the routing and processing time information is provided in Figure 3 


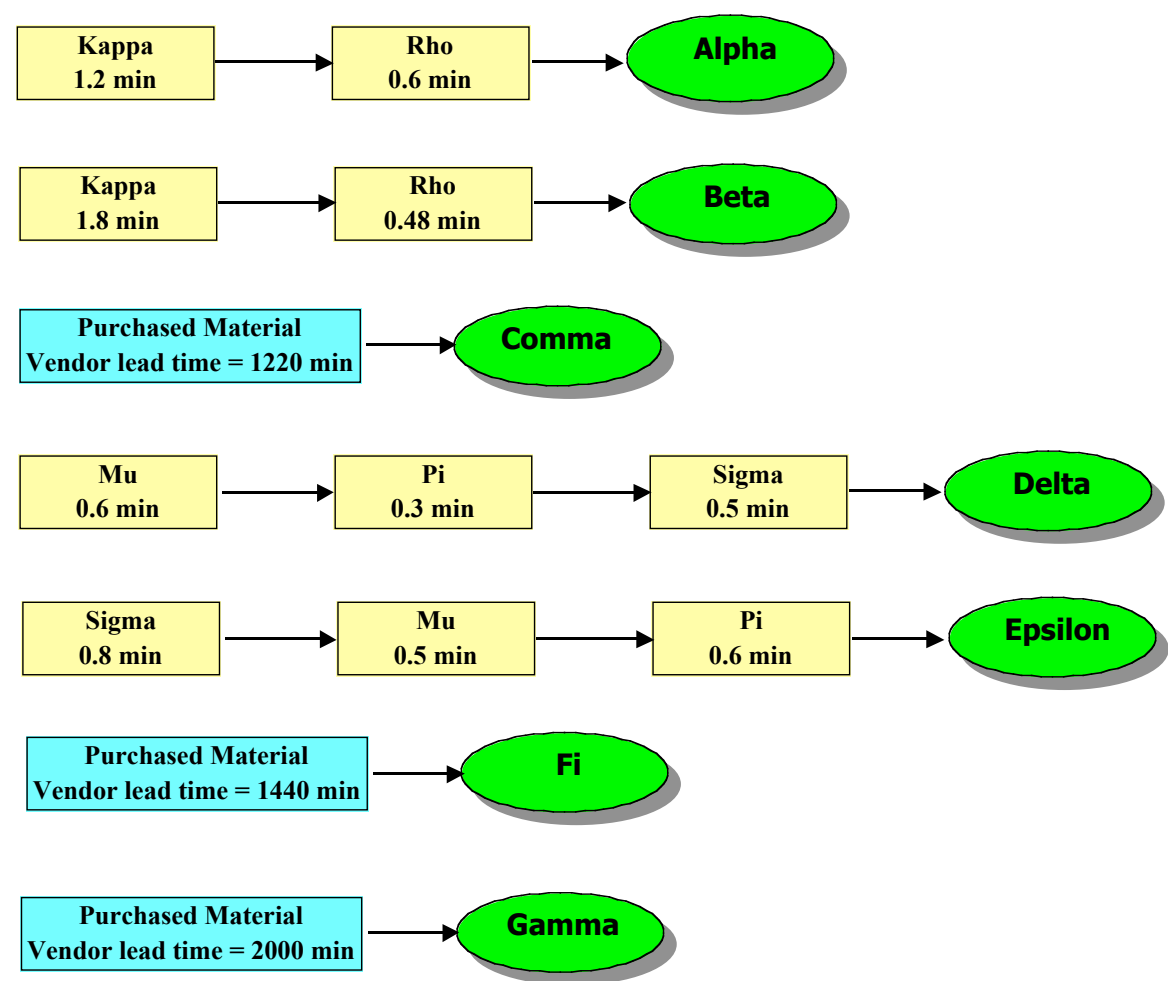

Figure 3: Routing and processing time information

The production planning is done on a weekly basis. At the beginning of the week, inventories are checked and orders are released both within the company and to the vendors. Through the week the processing takes place. Customer orders arrive based on a stochastic process that simulates seasonality, trend, and randomness. The parameters of this process are of course unknown to the students. As customer orders arrive, the orders are filled from inventory on hand. Customer orders may be filled partially if there is insufficient on hand inventory for the whole order. Unfilled customer orders are placed on file and filled when the product is available. The weekly cycle of activities is:

- release production and vendor orders,

- decide on overtime for the processes,

- simulate for a week (during this time these events occur: production in the facility, order fulfilment from the vendor, order arrival from the customer, and order fulfilment to the customer), and

- monitor the situation. 
The planner participates in this process beginning from week 20 and the game ends after week 32. A simulator written in Visual Basic and incorporated in an Excel spreadsheet simulates this scenario. The students interact with the simulator in the spreadsheet environment.

Profits are accumulated for every item in the customer order that is filled. For every item in the customer order that is late (filled after the day the order arrives), a penalty is charged per day. There are also costs associated with holding inventory (both finished and work in process) and with overtime work.

\section{Student task}

To play the game, the students only need to make decisions on order release and overtime on a weekly basis. The objective of the students is to maximise their total profits at the end of week 32 . After playing the game for a while, students find out that ordering on an ad-hoc basis leads them to financial ruin! They are asked to use past data for developing a forecast, which, through the material requirements planning process should help them in deciding how many parts / products to order and when. A capacity requirements planning module can help them decide how much overtime to order. Their specific assignment is to create a decision support system (DSS) for order release using these concepts They then use this DSS to play the game and see for themselves how MRP works to facilitate accurate order release, in synchronisation with the forecast demand (and to increase their financial performance!). They create the DSS within the spreadsheet environment of MRP-SIM Students don't need to do programming in Visual Basic, but they need to be proficient in using spreadsheet software. Learning to use spreadsheet software is an additional goal of this assignment.

\section{User interface}

The main screen of MRP-SIM is shown in Figure 4. The upper left corner shows the products currently being processed by the machines and their queues (for example, the process $\mathrm{Mu}$ is currently processing 3000 units of Epsilon). It also shows orders placed with the vendor. The lower part of the screen shows the current inventory position. Current pending customer orders are also shown. To play the game, the button Initialise Game is used to initialise. This causes a history of demand to be created up until week 20. The students can view the current inventory, work in progress, and vendor orders at this time. Next they need to decide on the orders to place for next week, their priorities, and overtime to authorise for the next week. Once they have made the decisions, they communicate it to the simulator by clicking on the Make / Alter Decisions button. 


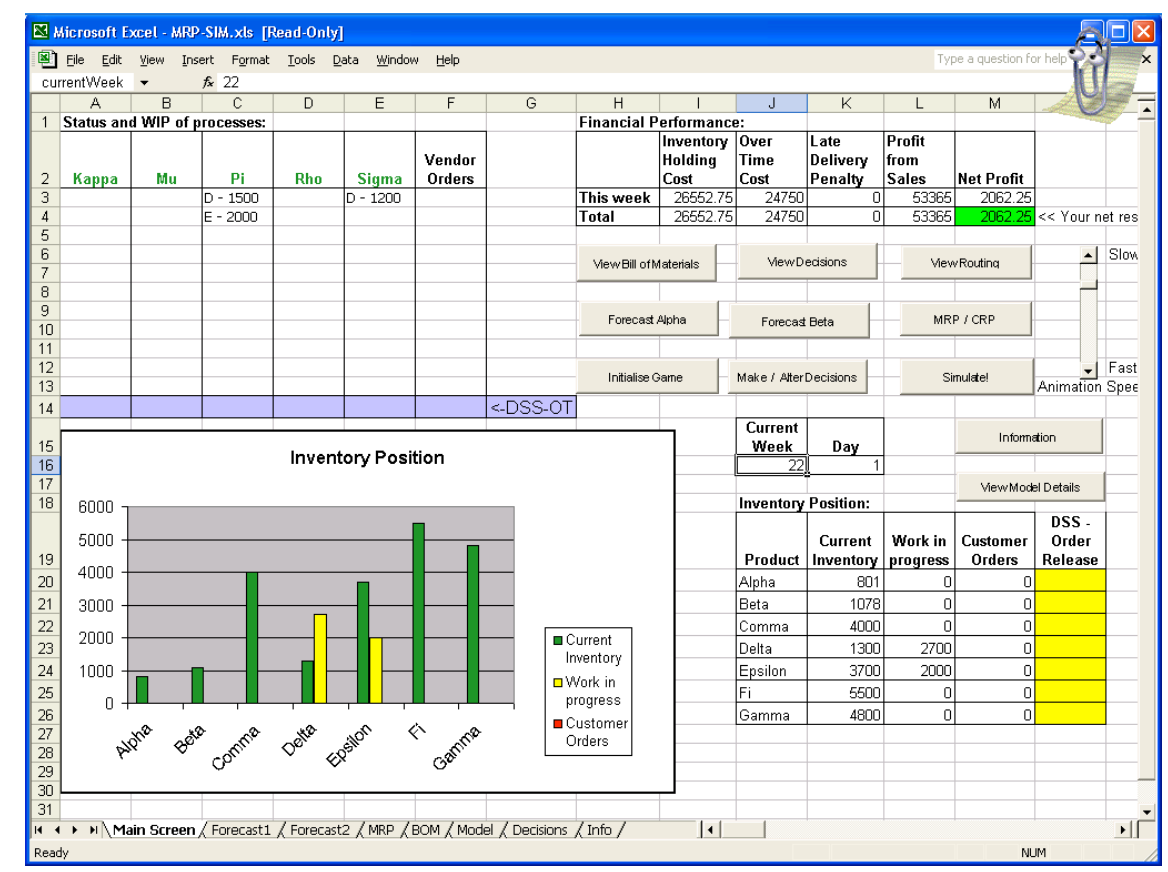

Figure 4: The main screen

Once the decisions are entered, they press the Simulate! button to let the production for the week begin, and to let the time advance to the next week. The queues of the machines, the finishing of the work, the inventory position, the arrival of customer orders, and the filling of the customer orders are animated on the screen. Profits are accumulated for every item in customer orders that is filled. For every late item a penalty is charged per day. There are also costs associated with holding inventory and with overtime work. The details of the model may be viewed by pressing the View Model Details button. At the end of the week the current and cumulative financial performance is shown at the top right of the screen (Figure 4 shows that a net profit of $\$ 2062.25$ was made at the end of week 21 . The students then make decisions for the next week and repeat the cycle.

\section{The assignment}

Students are asked to play the game in an ad-hoc manner, without any decision support, to familiarise them with the simulator and to see how well they can perform without the forecasting, MRP, and CRP models. They are then asked to build a DSS consisting of these models to help 
them play the game. In building the DSS they can create initial forecasts from the 20 weeks of historical data. The forecasts and the MRP need to be updated as new data becomes available. All this is done within the spreadsheet environment. The students are asked to hand in their DSS (in a diskette) and a semi-structured reflective essay on the game, their experiences, and their understanding of the concepts.

The assignment consisted of three steps:

Step 1. Familiarisation with the simulator. The students play the game in an ad hoc manner, guessing the decisions.

Step 2. Playing the game on a re-order point basis. The students try on different levels of re-order points and fixed order quantities.

Step 3. Playing the game with a DSS, built by the students. To do this, they use a forecasting model to forecast demand of the finished products. This is fed into the master production schedule

(MPS), which it explodes into the MRP for the components. The students then create the CRP model from the MRP model. This completes the DSS, which suggests the order quantities for all the items, and the overtime to order for all the processes.

Formal assessment for this assignment consists of reflective essay (50\% of the assignment marks) and the DSS (50\%). The class was split into self selected groups of 3 students. The development of the DSS was a group activity, but the reflective essay was an individual task. The assessment criteria were reflection breadth (number of activities or items discussed) and reflection depth (thoroughness of discussion, depth being more important than breadth), and completeness and correctness of the DSS work.

\section{Learning and the simulation}

The EL cycle (Figure 1) underpins many processes (Scott, 1990), including simulation. In the cycle, reflection is the stage that separates a simulation experience from tying it to models and concepts used to improve performance. While our students have some reflection skills, encouraged by some familiarity in our first year course with simple concepts such as Positive, Minus, Interesting (PMI) of Edward de Bono, and Single-loop (SLL) versus Double-loop Learning (DLL) (Figure 5) of Chris Argyris (Argyris,1977 ), reflection still appears to be the weakest link in their EL cycle, for which no formal instruction is given. Also, simulation models can be seen as devices to support reflection before action. We therefore chose reflection as a parallel, learning focus for this study. 


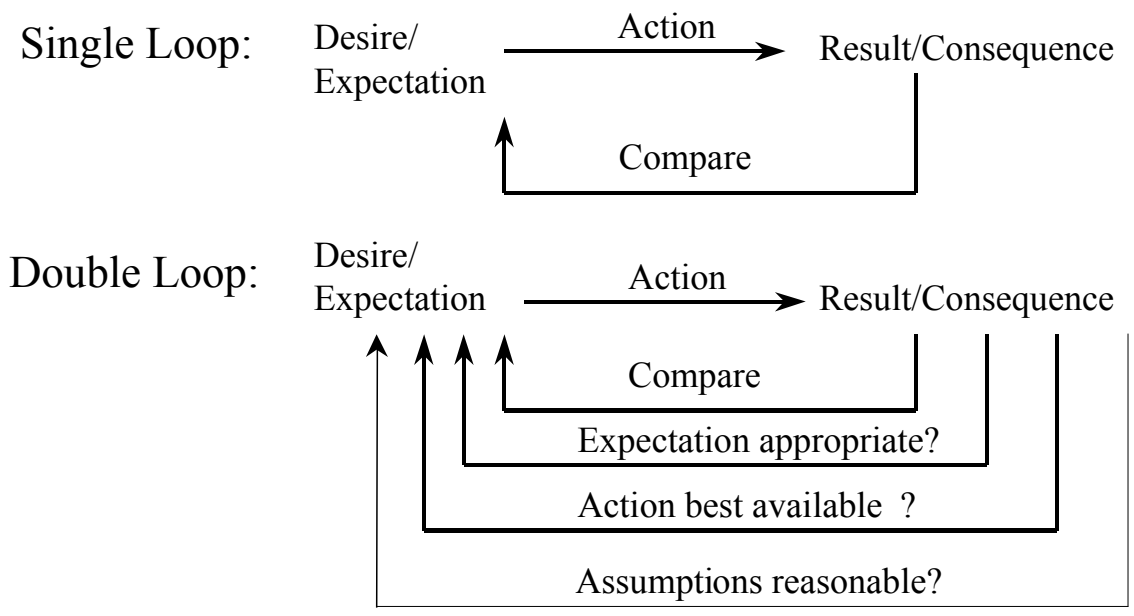

Figure 5: Single-loop versus double-loop learning

\section{We decided to:}

- track the main activities students used before and during each major step within the MRP-SIM assignment, using activity logs

- create time maps from the activity logs

- record the levels of reflection witnessed

- stimulate learning awareness by discussing, in class, the results with the students, before they finalised their reflective essays, which were part of the assessment scheme.

Tracking the main activities was done using a semi-structured, one page questionnaire we called an activity log (example in Appendix 1) - one for each major step in the assignment (see above). Each log asked students to record the time spent, and thinking behind, each significant task their group had undertaken.

Creating time maps of the steps was simply done by graphing tasks versus (proportion of) time spent, over the engagement. One class graph for each significant MRP-SIM engagement was created, using different colours for each student group.

With the MRP-SIM assignment requiring students to set levels of production, observe the result/outcome, and revise their estimates, potential levels of reflection were clearly related to Single-loop and Double-loop Learning. Four levels were set: (0) trial and error, to no plan, 
(1) discussed/predicted what would happen before numbers were entered (Sll), (2) questioned model or process being used to predict the result/outcome (Dll), and (3) questioned the process being used in step (2).

\section{Experiences in using the game in a teaching context}

This game and assignment combination was used in an operations management course offered at the final year of a Bachelor of Management Studies degree at the University of Waikato in Hamilton, New Zealand. The assignment was a part of the module covering production planning and control. The students were given the assignment after covering the concepts of MRP in the class. It is emphasised that we did not conduct a formal annual evaluation of the game since we had no control over the sample size and little control over when the course would be offered. Instead we assigned the game to the students as opportunities arose to do so and we collected the students' and our own experiences after the event for reflection and potential modifications. At the end of a 1998 course, 10 of the 18 students taking the course evaluated the game anonymously. After a 2002 course, 5 of the 6 students did a similar evaluation. There were differences between these two offerings, as we tried to improve after the first instance of using the game. One major difference was that the activity logs were only instituted in 2002. In the following sections we offer the insights we gained.

The assignment was distributed in class and the first lab session held, 14 days later. As "entry tickets", the activity logs for ad-hoc and re-order point running of the simulation were collected. The second lab session was held, 2 days later. The two lab sessions were essentially help sessions, offering individual help to the class members in creating their DSS. Students can often be unsure of the concepts emphasised in this assignment, or even the purpose of the DSS. Many students struggle to acquire the level of spreadsheeting skills needed for the assignment. The two lab sessions offered instructions in these matters.

The spreadsheet files and the DSS activity logs were then submitted for assessment. Discussion of the results and feedback was given in class, 21 days before their reflective essay on the assignment was submitted. The reflective essay was for three pages of thoughtful responses to reflective questions we had provided.

There were six students taking this paper in 2002; they were given three activity logs to fill in, corresponding to three ways, or steps, of playing the game: in an ad hoc way, with reorder points for each items, and with 
the help of the DSS created by them. Students filled in the time they spent on various activities. All possible activities were identified in the logs, including the four dealing with reflection, but the students were not told the learning levels of the logged items until the discussion of results and feedback session. This session was deliberately held before the final reflective essays were submitted.

Figure 6 shows the self-reported total time spent by students on the four levels of learning in carrying out the assignment. Similar graphs were also available for individual steps.

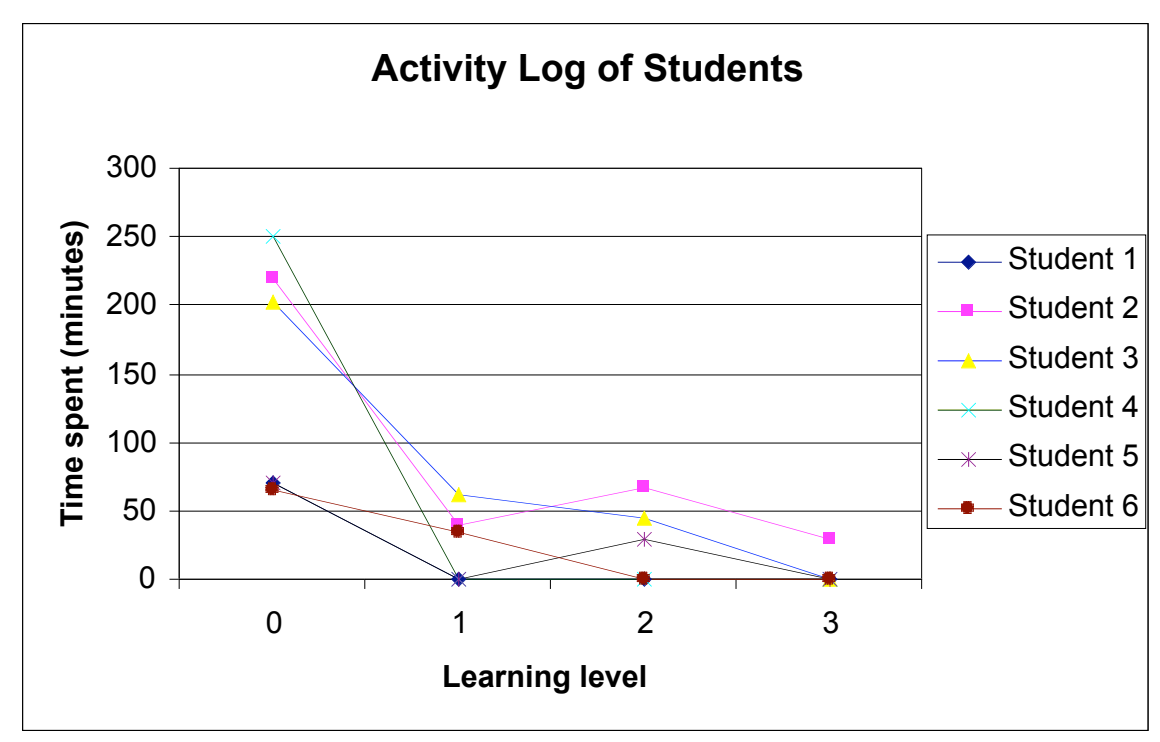

Figure 6: Self reported activity log for all steps

When presented with the learning levels of their activities and the time they spent on activities, most of the students were surprised at the very high time they spent on level 0 activities (trial and error or without a plan), as against single loop or double loop learning.

\section{Student evaluations}

The students were asked to assess the simulation game in the context of their normal end of course anonymous course and teacher assessment. Their average ratings on a scale of $(1=$ strongly agree, $5=$ strongly disagree) is presented below in Table 1 . 
Table 1: Student evaluation of the game

\begin{tabular}{|l|c|c|}
\hline Statement & $\begin{array}{c}\text { Average } \\
\text { agreement } \\
\text { rating 1998 }\end{array}$ & $\begin{array}{c}\text { Average } \\
\text { agreement } \\
\text { rating 2002 }\end{array}$ \\
\hline $\begin{array}{l}\text { Simulation gaming was instructive for learning } \\
\text { production planning }\end{array}$ & 2.0 & 1.2 \\
\hline I enjoyed playing the simulation game & 1.9 & 1.6 \\
\hline I put a lot of effort in playing the simulation game & 2.1 & 1.4 \\
\hline $\begin{array}{l}\text { The simulation game represents fairly well the } \\
\text { decision making faced by real production planners }\end{array}$ & 2.1 & 1.8 \\
\hline $\begin{array}{l}\text { I found the simulation game challenging } \\
\text { There was a strong sense of make believe in playing } \\
\text { the game }\end{array}$ & 1.8 & 1.4 \\
\hline $\begin{array}{l}\text { I felt the game enhanced my understanding of } \\
\text { planning and control }\end{array}$ & + & 2.0 \\
\hline $\begin{array}{l}\text { The game helped me improve my use of spreadsheet } \\
\text { software }\end{array}$ & + & 1.2 \\
\hline The game assignment should be retained for next year & 1.8 & 1.0 \\
\hline
\end{tabular}

t Not included in the 1998 evaluation

Generally, the students found the assignment quite challenging. But they felt that they learnt the MRP concepts pretty well. Since the students had some familiarity with spreadsheets, the spreadsheet format of the game helped in gaining student acceptance. Their evaluations bore testimony to this. Some student comments, collected in 2002 from their reflective essays, are given below.

\section{Student A:}

The next consideration was that the game opened my perspective to the complexity of working within a production environment. It was insightful to see all of the considerations that need to been (sic) thought of such as overtime, holding costs and late delivery costs. Also the fact that at the end of the game it was not full proof (sic, the student meant 'fool-proof') in its recommendations supported the difficult nature of production management.

\section{Student B:}

Therefore, using the DSS helped me play the game better and also my profits had increased as well (i.e. started making profits rather than loss). I believe the reason for improved results was due to taking more accurate and precise figures into account when planning the future productions. However, with DSS, decisions were still based on using my own judgment and the game was still played with a great deal of uncertainty due to reliance on forecasting figures. But to make it more realistic in the essence to make the user of the MRP Simulation believe it is the real world and to be able to imagine themselves in that environment, I think adding more financial data such as how much overtime and late delivery is really costing for each component (not just the total), and more costing information would enrich a persons mind. 
Student C:

At the beginning I did not know where to start. However, with general knowledge of production planning that I had learned from the lectures, I continuously read and followed the instructions provided. At the same time, I familiarised myself with the simulation software by using MS Excel application to get a sense out of it, which was quite difficult for me. Then, I found there were some parts of MRP that were separated by sheets or tabs like; Bill of Materials, MRP / CRP, Routing, Order Release, and Forecasting, which in the beginning I did not see how I can relate these tasks together.

The comments indicate that the students did achieve a good understanding of the production planning concepts, which was the main goal of this exercise. Some students also developed an understanding of the uncertainties involved and gained an appreciation of the fact that a DSS provides decision support, but does not supersede human decision making. Even though the students generally felt that the assignment improved their spreadsheet skills, their skills before the assignment ranged from a proficient level to a beginner's level. This obviously impacted their attitude to the spreadsheet work, which they found overwhelming to underwhelming, depending on their previous experience. Most students found that this assignment took up much more time than they would have expected or wished, relative to the $4 \%$ assessment weighting it carried.

Suggested improvements included making a competition out of it, with the highest profit making students gaining rewards and high marks. Another student (accounting) suggested more detailed reporting of the financial outcome of the game.

\section{Conclusion}

In this paper we presented a spreadsheet-based simulator for teaching and learning production planning and control concepts such as forecasting, material requirements planning, order review and release. The game received a favourable response from the students. The spreadsheet format helped gain acceptance. Although the students were not judged on their financial performance, they did develop a rivalry to gain the highest profit. This substantially increased the motivation in playing the game. A focus on levels of reflection attained added a parallel learning focus.

This game enhances the understanding of PPC concepts as well as providing the students with an opportunity to build a decision support system that provide the game players with detailed modelling and decision making capability, and to learn the difference between ad hoc 
decisions and model based decisions. Learning spreadsheet modelling is an additional educational benefit from the game. Vaszonyi (1993) and Plane (1994) present forceful arguments for using spreadsheets in management science and operational research.

The low proportion of time spent on reflection - making sense of action, connecting theory, and planning for further action - supports the view that our students should benefit from greater understanding of reflection and its praxis before playing the game. There are four aspects we have identified that could be added to the learning awareness aspect in the future:

- investigating if time spent developing spreadsheeting skills correlates with reflection patterns witnessed;

- recording the order in which tasks were done, although this would complicate recoding and analysis;

- relating time maps and ordering of tasks to learning styles;

- requiring more specific reflection on the reflective aspects in the final essay;

- discussing with future classes taking the assignment, the outcomes from this year, thereby seeding interest and awareness of reflection pre-assignment.

Our study supports previous studies that have shown significant benefits from using simulation gaming as a pedagogical tool. Our students did achieve their learning objectives through the simulation. They also expressed a positive attitude towards the "game". Thus while we believe that the simulation achieved its purpose, we emphasise that this was just one of the many modules in this course. Other modules used other learning techniques, such as debating, case studies, report writing, etc. The simulation was particularly suited for its learning task, the other techniques were chosen with their own goals in mind. We believe that positive interactions between teaching and learning tools should be used in this way to achieve the overall goals of a course. Further, such interdependent interactions with the students can greatly enhance their ability to learn in the outside, less structured environments. This has particular significance for subjects aiming to transform students into analysts and consultants.

The simulation model and the related assignment may be obtained by writing to the authors. The simulation game is included in a list of exemplar learning designs based on information and communication technologies compiled by the Australian Universities Teaching Committee. This can be accessed at the URL:

http:/ / www.learningdesigns.uow.edu.au/exemplars/info/LD14/index.html 


\section{References}

Argyris, C. (1977). Double loop learning in organizations. Harvard Business Review, Sept-Oct, 115-125.

Biggs, W. D. (1987). Functional business games. Simulation and Games, 18(2), 242267

Boseman, F. G. and Schellenberger, R. E. (1974). Business gaming: An empirical appraisal. Simulation and Games, 5(4), 383-402.

Burgess, T. F. (1991). The use of computerized management and business simulation in the United Kingdom. Simulation and Gaming, 22(2), 174-195.

Churchill, G. (1970). Joblot: A Production Management Game. UK: Macmillan.

Faria, A. J. (1987). A survey of the use of business games in academia and business. Simulation and Games, 18(2), 207-224.

Faria, A. J. (1990). Business simulation games after thirty years: Current usage levels in the United States. In J. W. Gentry (Ed), Guide to Business Gaming and Experiential Learning, 36-47. London: Nichols/GP Publishing.

Gilgeous, V. and D'Cruz, M. (1996). A study of business and management games. Management Development Review, 9(1), 32-39.

Kibbee, J. M., Craft, C. J. and Nanus, B. (1961). Management Games: A New Technique for Executive Development. New York: Reinhold.

Kolb, D.A. (1984). Experiential Learning: Experience as the Source of Learning and Development. USA: Prentice-Hall.

Lane, D. C. (1995). On a resurgence of management simulations and games. Journal of the Operational Research Society, 46, 604-625.

McKenna, R. J. (1991). Business computerized simulation: The Australian experience. Simulation and Gaming, 22(1), 36-62.

Mize, J. H, Herring, B. E., Cook, C. L., Chun, M. S. and White, C. R. (1971). Production System Simulator (PROSIM V): A User's Manual. USA: Prentice-Hall.

Parsuraman, A. (1981). Assessing the worth of business simulation games. Simulation and Games, 12(2), 189-200.

Plane, D. R. (1994). Spreadsheet power. OR/MS Today, 20, 32-38.

Raia, A. P. (1966). A study of the educational value of management games. Journal of Business, 39(3), 339-352.

Ruohomäki, V. (1995). Viewpoints on learning and education with simulation games. In J. O. Riis (Ed), Simulation Games and Learning in Production Management, 13-25. UK: Chapman and Hall.

Scott, J. L. (1990). OR methodology and the learning cycle. OMEGA International Journal of Management Science, 18(5), 551-553. 
Scott, J. L. (2002). Stimulating awareness of actual learning processes, Journal of the Operational Research Society, 53(1), 2-10.

Vaszonyi, A. (1993). Where we ought to be going: The potential of spreadsheets. Interfaces, 23, 26-39.

Wolfe, J. and Guth, F. R. (1975). The case approach versus gaming in the teaching of business policy: An experimental evaluation. Journal of Business, 48(3), 349364.

Wolfe, J. (1975). A comparative evaluation of experiential approach as a business policy learning environment. Academy of Management Journal, 18, 442-452

Wolfe, J. (1993). A history of business teaching games in English-speaking and post-socialist countries: The origination and diffusion of a management education and development technology. Simulation and Gaming, 24(4), 446-463.

$\mathrm{Wu}, \mathrm{N}$. L. (1989). Understanding production through human simulation: Experiencing JIC (just-in-case), JIT (just-in-time), and OPT (optimisedproduction-technology) production systems, International Journal of Operations and Production Management, 9(1), 27-34.

Yeo, G. K. and Nah, F. H. (1992). A participants' DSS for a management game with a DSS generator, Simulation and Gaming, 23(3), 341-353.

\section{Appendix 1: Activity log sample}

0342.576 Advanced Operations Management. Assignment 1, Part B.

Production Planning at "Greek Manufacturing Company"

\begin{tabular}{|l|l|l|}
\hline \multicolumn{2}{|c|}{ Individual ACTIVITY LOG for step 1: Playing the game in an ad-hoc manner } \\
\hline \multicolumn{1}{|c|}{ ACTIVITY: } & $\begin{array}{c}\text { Mins } \\
\text { spent }\end{array}$ & $\begin{array}{c}\text { Thinking associated (and } \\
\text { outcomes) }\end{array}$ \\
\hline Read the assignment & & \\
\hline Wrote down questions and thoughts & & \\
\hline Played around inside the spreadsheet file & & \\
\hline $\begin{array}{l}\text { Put in some rough numbers into the } \\
\text { spreadsheet, just to see what would happen }\end{array}$ & & \\
\hline $\begin{array}{l}\text { Developed expectations about the results of } \\
\text { running this simulation }\end{array}$ & & \\
\hline $\begin{array}{l}\text { Compared simulation results with your } \\
\text { predictions/ expectations }\end{array}$ & & \\
\hline $\begin{array}{l}\text { Openly questioned processes you were } \\
\text { using in forming your expectations }\end{array}$ & & \\
\hline $\begin{array}{l}\text { Sought further information about specific } \\
\text { things }\end{array}$ & & \\
\hline Discussed the assignment with my group & & \\
\hline $\begin{array}{l}\text { Worked out numbers before running the } \\
\text { simulation }\end{array}$ & & \\
\hline
\end{tabular}




\begin{tabular}{|l|l|l|}
\hline $\begin{array}{l}\text { Changed my/our approach ..... times } \\
\text { during the 32 weeks }\end{array}$ & \\
\hline $\begin{array}{l}\text { Predicted what would happen before we } \\
\text { simulated }\end{array}$ & & \\
\hline $\begin{array}{l}\text { Questioned the processes being used to } \\
\text { 'Make/alter decisions' }\end{array}$ & & \\
\hline $\begin{array}{l}\text { Questioned the entire approach you were } \\
\text { using }\end{array}$ & & \\
\hline Any other activities (state here) & & \\
\hline
\end{tabular}

* Think of the page as a map of what you did, with enough detail for the reader to be able to understand all the activities you followed and your thinking behind it. Tell it truthfully, as there is no "right answer" here, just a conscientious completion of the picture of your activities.

Profit achieved in your best simulation run in an ad-hoc manner $=\$$

Read through the page now, speaking it out in your head as if you were telling someone what you did, and the thinking behind it.

Chuda Basnet and John L. Scott
Department of Management Systems, University of Waikato
Private Bag 3105, Hamilton 2020, New Zealand
Telephone: +64 78384562 Fax: + 6478384270
Email: chuda@waikato.ac.nz, jls@waikato.ac.nz
http:/ / www.mngt.waikato.ac.nz/school/staff/staffhome.asp?ident=732\&user=JLS

